Matti Erjala

Sokerijuurikkaan Tutkimuskeskus

Korvenkyläntie 201

25170 KOTALATO

matti.erjala@danisco.com

\title{
Suurten akselipainojen vaikutus sokerijuurikaspellon tiivistymiseen
}

\section{Suurten akselipainojen projekti}

Suuret akselipainot-projektissa selvitetään sokerijuurikkaan korjuukoneen painon vaikutusta sokerijuurikasmaan tuottokuntoon. Koemateriaali kerätään käytännön viljelmiltä, joissa yksirivisillä korjuukoneilla nostettuja lohkoja verrataan kuusirivisillä nostettuihin.

\section{Johdanto}

Sokerijuurikas on syväjuurinen kasvi, jonka juuret kuohkeassa maassa, ulkomaisten tutkimusten mu- kaan, saattavat ulottua jopa 180 - $250 \mathrm{~cm}$ syvyyteen asti (Wadleigh 1950). Suomessa kokemustem- me mukaan juuriston syvyys ulottuu selvästi matalammalle tasolle $(30-150 \mathrm{~cm})$.

Sokerijuurikas on vaativa viljelyskasvi, jonka sadontuottokyky on parhaimmillaan maassa, joka täyttää seuraavat vaatimukset:

\section{Oikea maalaji}

a. Hietasavi (HtS), b. Liejusavi (LjS), Aitosavi (AS), Hiuesavi (HeS) c. Hieno hieta (HHt), Karkea hieta (KHt), Hiue (He) ja eloperäiset maat d. Hiesusavi (HsS), Hiesu (Hs), Hieno hiekka (HHk)

\section{Hyvin ojitettu}

Suomalaisen sokerijuurikkaan sadontuottokykyä rajoittaa eniten kasvukautemme lyhyys. Kasvukau- den pituus on tekijä, johon voidaan vaikuttaa merkittävästi. Kuten prof. Tuomo Karvonen väitöskir- jassaan totesi, hyvin ojitetuille pelloille päästään kylvöille jopa useita viikkoja aikaisemmin kuin huonosti ojitetuille pelloille. Tämän ovat todenneet myös useimmat sokerijuurikkaanviljelijät, jotka ovat voimakkaasti investoineet pellon ojituksen parantamiseen. Hyvin ojitetuilla pelloilla kasvukausi pitenee sekä alusta että lopusta.

\section{Neutraali maa}

Sokerijuurikkaan happamuuden sietokyky on hyvin heikko. Mitä happamampi maa, sitä kituliaam- min sokerijuurikas kasvaa.

\section{Kuohkea ruokamultakerros}

Savimaan ruokamullan pitäisi ennen kaikkea olla ilmavaa (ilmahuokosia $>10 \%$ ), jotta sokerijuurik- kaan hiussuonet kykenisivät tehokkaasti hyödyntämään maassa olevia vesi- ja ravinnevaroja (Aura 1974 ja 1983).

\section{Jankko ja pohjamaa huokoisia}

Sadontuottokyvyltään hyville maille on tyypillistä, että ruokamultakerroksen lisäksi jankko ja pohja- maa ovat kunnossa. Jankossa pitää olla juuren mentäviä aukkoja, jotta juuristo kykenee tunkeutu- maan pohjamaahan. Pohjamaan pitää olla riittävän huokoinen, jotta juuret kykenevät tarpeen vaa- tiessa etenemään syvemmälle maaprofiilissa. Etenkin pitkien poutajaksojen aikana juurten mahdolli- suus kasvaa pohjamaahan on ensiarvoisen tärkeää.

Ruokamultakerroksen rakenne- ja tiivistymisongelmat ovat usein korjattavissa. Jankon ja pohja- maan rakenne ja tiivistymisongelmat ovat astetta vaikeampia kuin ruokamultakerroksen, sillä jank- koon ja pohjamaahan aiheutettu vaurio näyttäisi olevan suhteellisen pysyvää tai jopa peruuttamaton- ta (Alakukku 
1997). Ruotsissa on mm. prof. Inge Håkansson todennut, että nykyinen mekanisoitu viljelytekniikka on tiivistänyt koko olemassaolonsa aikana Ruotsin sokerijuurikaspeltojen jankkoa siinä määrin, että se jo merkittävästi alentaa nykyisiä juurikassatoja (1996). Suomessa vastaavaa selvitystä ei ole tehty. Kaikki tämä antaa viitteitä siitä, että jos haluamme pitää omien peltojemme sa- dontuottokyvystä kiinni, meidän on jatkossa huolehdittava myös siitä, että jankon ja pohjamaan asiat ovat kunnossa.

Jankon ja pohjamaan rakennevaurioiden vakavuus johtuu usein vain kahdesta eri tekijästä; olo- suhteista ja akselipainosta. Pohjamaan vaurioitumisriski kasvaa, jos 5 tonnin akselipaino ylittyy maan ollessa märkää (Andersson \& Håkansson 1966). Suomalaisillekin pelloille ovat tulleet 6-riviset itsekulkevat korjuukoneet, joiden akselipaino saattaa nousta jopa 20 tonniin. On aivan selvää, että pohjamaan vaurioitumisriski on olemassa, ainakin nykyisen tietämyksen valossa, meidän ohutmul- taisilla juurikaspelloillamme, jos käytetään näin suuria nostokoneita.

\section{Maan fosforireservit riittävät}

Sokerijuurikkaan nopean alkukehityksen vuoksi on tärkeää, että maan fosforireservit ovat riittävät (P-luku > 20 mg/l maata)(Allison \& Chapman 1995).

\section{Aineisto ja menetelmät}

Vuonna 1999 perustettiin ns. suurten akselipainojen projekti, jonka tavoitteena on osoittaa korjuuko- neen akselipainon vaikutus maan rakenteeseen ja satoon. Työryhmän asiantuntijaksi kutsuttiin eri- koistutkija Laura Alakukku Maa - ja elintarviketalouden tutkimuskeskuksesta Jokioisista. Hän on tehnyt väitöskirjansa suurten akselipainojen vaikutuksesta maan rakenteeseen, joten hänen suostu- muksensa projektin asiantuntijajäseneksi oli tietenkin meille ensiarvoisen tärkeää.

Valitsimme maaperäolosuhteiltaan 22 mahdollisimman samanlaista lohkoparia, jotka erosivat merkittävästi toisistaan vain nostotavan mukaan. Toinen oli nostettu 1-2 rivisellä korjuukoneella ja toinen 6-rivisellä korjuukoneella. Lohkoparit sijaitsevat kaikki savimailla Salon lähiympäristössä ja Vakka-Suomessa. Vuonna 2000 syksyllä mukaan otettiin 5 kevyen maan lohkoparia Hämeestä. Jo- kaiselta lohkolta on valittu neljä eri kohtaa, joista tehdään vuosittain tarvittavat mittaukset, näyttee- notot sekä koekorjuut. Koejärjestely on sellainen, että näkemyksemme mukaan pääsemme kiinni sii- hen, onko akselipainolla ja nosto-olosuhteilla merkitystä sokerijuurikaspellon tuottokuntoon. Projek- ti on monivuotinen, jotta näkisimme kehityksen suunnan ja nopeuden.

Vuosittain kaikilta lohkoilta kerätään talteen kaikki se taustatieto, joka mahdollisesti on ollut vai- kuttamassa sadon määrään ja laatuun.

\section{Tulokset ja tulosten tarkastelu}

Vuoden 2001 koemateriaalin analysointi ja laskenta on vielä pahasti kesken, joten tässä yhteydessä on turvauduttava pääasiassa vuoden 2000 tuloksiin. Vuonna 2000 oli vain 17 parivertailua, joilta korjattiin sokerijuurikassato.

Tässä yhteydessä on mielenkiintoista tarkastella niitä viittä paria, joista ei saatu täydellistä pari- vertailua v. 2000.

$\begin{array}{lll} & \text { 1-rivinen } & \text { 6-rivinen } \\ \text { Pari 11 } & \text { Sokerijuurikas } & \text { Vilja } \\ \text { Pari 12 } & \text { Sokerijuurikas } & \text { Herne } \\ \text { Pari 14 } & \text { Sokerijuurikas } & \text { Vilja } \\ \text { Pari 16 } & \text { Sokerijuurikas } & \text { Sokerijuurikas } \\ \text { Pari } 21 & \text { Sokerijuurikas } & \text { Vilja }\end{array}$

Parien 11, 12 ja 14 kohdalla 6-rivisille lohkoille kylvettiin välikasvi hyvin todennäköisesti sen vuok- si, ettei pelto muokkautunut kunnolla keväällä, jotta se olisi kelvannut sokerijuurikkaan kylvöalus- taksi. Ruokamultakerroksen mururakenne oli ilmeisesti näissä tapauksissa pahasti vaurioitunut edel- lisen syksyn märissä nosto-olosuhteissa. Pari 16 kohdalla 6-rivisellä nostettu lohko nostettiin vahin- gossa koneella ennen kuin ehdimme tehdä koeruutujen korjuut ko. lohkolta. Parin 21 kohdalla 6-ri- visen lohkon viljelijä oli jo 
etukäteen ilmoittanut meille, että hän noudattaa ko. lohkolla sopivaksi katsomaansa viljelykiertoa.

Kuten taulukoista 1 ja 2 voidaan havaita, niin tässä yhteydessä tarkasteltavat lohkoparit olivat maaperäominaisuuksiensa suhteen lähes identtiset. Lohkoparien valitsemisessa käytimme hyväksi paikallisen juurikaskonsulentin asiantuntemusta. Aika usein vertailulohkot erottaa toisistaan vain oja.

Taulukko 1. Pinta- ja pohjamaan maalajitefraktiot

\begin{tabular}{cclcl} 
& \multicolumn{2}{c}{$\mathbf{0}-\mathbf{3 0}$ cm } & \multicolumn{3}{c}{$\mathbf{3 0} \mathbf{- 6 0}$ cm } \\
& 1-riv. 6-riv. & \multicolumn{2}{c}{ 1-riv. 6-riv. } \\
Humus-\% & 9.5 & 7.2 & 3.9 & 3.8 \\
Sr-\% & 0.9 & 0.3 & 0.1 & 0.1 \\
KHk-\% & 2.7 & 2.2 & 1.6 & 1.0 \\
HHk-\% & 2.9 & 3.1 & 2.2 & 2.5 \\
KHt-\% & 17.4 & 17.5 & 13.0 & 14.0 \\
HHt-\% & 12.0 & 12.1 & 11.6 & 10.5 \\
KHs-\% & 11.4 & 11.1 & 10.4 & 11.0 \\
HHs-\% & 11.2 & 11.8 & 11.7 & 11.9 \\
S-\% & 41.5 & 41.9 & 49.2 & 49.1
\end{tabular}

Taulukko 2. Pinta-ja pohjamaan viljavuustiedot

\begin{tabular}{lccccc} 
& \multicolumn{2}{c}{$\mathbf{0}-\mathbf{3 0} \mathbf{~ c m}$} & \multicolumn{3}{c}{$\mathbf{3 0} \mathbf{- 6 0}$ cm } \\
& \multicolumn{2}{c}{ 1-riv. 6-riv. } & \multicolumn{3}{c}{ 1-riv. 6-riv. } \\
$\mathrm{pH}$ & 6.94 & 6.79 & & 5.98 & 6.01 \\
$\mathrm{P} \mathrm{mg} / \mathrm{l}$ & 53.0 & 46.4 & 9.3 & 14.3 \\
$\mathrm{~K} \mathrm{mg} / \mathrm{l}$ & 169 & 177 & 157 & 168 \\
$\mathrm{Na} \mathrm{mg/l}$ & 40.5 & 47.2 & 36.9 & 45.8 \\
$\mathrm{Mg} \mathrm{mg} / \mathrm{l}$ & 237 & 249 & 479 & 462 \\
$\mathrm{Ca} \mathrm{mg} / \mathrm{l}$ & 4521 & 3975 & 2121 & 2273 \\
Johtoluku & 2.38 & 2.15 & 1.91 & 1.99
\end{tabular}

Taulukko 3. Satotiedot v. 2000

$\begin{array}{lcccc} & & \text { 1-riv. } & \text { 6-riv. } & \text { F-arvo } \\ \text { Juurisato } & \mathrm{t} / \mathrm{ha} & 40.8 & 40.8 & 0.00 \\ \text { Sokerisato } & \mathrm{kg} / \mathrm{ha} & 7110 & 7206 & 0.34 \\ \text { Kiteytyvä sokerisato } & \mathrm{kg} / \mathrm{ha} & 5981 & 6080 & 0.51 \\ \text { Juurikkaita } & 1000 \mathrm{kpl} / \mathrm{ha} & 97.6 & 104.0 & 13.39^{* * *} \\ \text { Sokeri-\% } & & 17.42 & 17.67 & 7.80^{* *} \\ \text { Amino-N mg/100 g.j. } & & 21.2 & 19.5 & 4.00^{*} \\ \text { Kalium me/100 g.j. } & & 4.87 & 4.85 & 0.05 \\ \text { Natrium me/100 g.j. } & & 0.76 & 0.74 & 0.15 \\ \text { Saanto-\% } & & 84.1 & 84.4 & 1.29\end{array}$

Kuten taulukosta 3 voidaan havaita, niin juurisato, sokerisato ja kiteytyvä sokerisato olivat kummas- sakin ryhmässä yhtäsuuret. Kasvutiheys 6-rivisten ryhmässä on ollut kuitenkin jostakin syystä sel- västi korkeampi kuin 1-rivisten ryhmässä (+6.6 \%). Tämä on heijastunut sokerijuurikkaan laatuar- voihin siten, että 6-rivisten ryhmän juurikkaat ovat olleet merkittävästi sokeripitoisempia ja ne ovat sisältäneet vähemmän sokerin saantoa haittaavia epäpuhtauksia - aminotyppeä, kaliumia ja natriumia kuin 1-rivisten ryhmän juurikkaat.

Penetrometrimittaukset tehtiin kaikilta lohkoilta pääosin kesä-heinäkuun aikana sekä v. 2000 että 2001. Lohkoparit mitattiin aina saman päivän aikana, jotta maan kosteustila ei aiheuttaisi tuloksiin systemaattista virhettä. Mittaus tehtiin metallisauvalla, jonka päässä oli halkaisijaltaan 12.8 mm:n kartio. Kullakin lohkolla oli 4 ennalta valittua mittauskohtaa, jotka ovat pysyviä koko projektin ajan. Mittaus aloitettiin riviltä 3 ja lopetettiin riville 17. Mittauksia tehtiin $15 \mathrm{kpl} /$ ruutu. Kerranneruutuja lohkolla oli neljä, joten koko lohkolta tehtiin vuosittain 60 mittauspistoa. Sauva työnnettiin kohti- suoraan maahan ja mitattiin työntövoima $3.5 \mathrm{~cm}: n$ välein aina $52.5 \mathrm{~cm}: n$ syvyyteen asti. Yksi pisto tuotti 15 lukua. Lohkolta saatiin siis yhteensä 15*60=900 lukua/vuosi. Tulokset on esitetty taulukos- sa 4. Ensimmäisenä vuonna suurten akselipainojen tiivistymä näkyy sekä pinta että pohjamaassa.

Toisena vuonna vaikutus on edelleen kumuloitunut (Alakukku \& Elonen 1995).

Taulukko 4. Penetrometrimittausten tulokset v. 2000 ja 2001. 6-rivinen verrattuna 1-riviseen. 15 täydellistä paria.

Mittaussyvyys
cm
3.5
7.0

$\begin{array}{lc}\quad \text { v. } 2000 & \\ \text { Sanallisesti } & \text { F-arvo } \\ \text { Yhtäsuuri } & 0.64 \\ \text { Kuohkeampi } & 49.08^{* * *}\end{array}$

v. 2001

$\begin{array}{cc}\text { Sanallisesti } & \text { F-arvo } \\ \text { Tiiviimpi } & 4.19^{*} \\ \text { Yhtäsuuri } & 2.27\end{array}$




$\begin{array}{lllll}10.5 & \text { Tiiviimpi } & 10.94^{* * *} & \text { Tiiviimpi } & 37.12^{* * *} \\ 14.0 & \text { Tiiviimpi } & 28.68^{* * *} & \text { Tiiviimpi } & 71.10^{* * *} \\ 17.5 & \text { Tiiviimpi } & 15.98^{* * *} & \text { Tiiviimpi } & 51.03^{* * *} \\ 21.0 & \text { Tiiviimpi } & 7.07^{* *} & \text { Tiiviimpi } & 10.07^{* * *} \\ 24.5 & \text { Yhtäsuuri } & 3.49 & \text { Yhtäsuuri } & 0.93 \\ 28.0 & \text { Kuohkeampi } & 30.21^{* * *} & \text { Kuohkeampi } & 20.80^{* * *} \\ 31.5 & \text { Yhtäsuuri } & 1.51 & \text { Yhtäsuuri } & 0.00 \\ 35.0 & \text { Yhtäsuuri } & 3.61 & \text { Tiiviimpi } & 11.57^{* * *} \\ 38.5 & \text { Tiiviimpi } & 28.27^{* * *} & \text { Tiiviimpi } & 20.87^{* * *} \\ 42.0 & \text { Tiiviimpi } & 26.70^{* * *} & \text { Tiiviimpi } & 37.01^{* * *} \\ 45.5 & \text { Tiiviimpi } & 32.46^{* * *} & \text { Tiiviimpi } & 57.57^{* * *} \\ 49.0 & \text { Tiiviimpi } & 41.11^{* * *} & \text { Tiiviimpi } & 59.43^{* * *} \\ 52.5 & \text { Tiiviimpi } & 42.26^{* * *} & \text { Tiiviimpi } & 49.36^{* * *}\end{array}$

Kuten jo johdannosta kävi ilmi, niin sokerijuurikkaan kasvuun vaikuttavat hyvin monet ulkoiset te- kijät. Regressioanalyysin keinoin haettiin kaikki ne tekijät, jotka merkittävästi vaikuttivat juurisadon vaihteluun eri paikkojen kesken. Analyysin mukaan vuoden 2000 juurisadon vaihtelua aiheuttivat ti- lastollisella varmuudella seuraavat tekijät (kuva 1):

1. Kylvöajankohta

2. Ruokamultakerroksen $\mathrm{pH}$

3. Nosto-olosuhteet edellisenä syksynä

4. Ajokertojen määrä toukotöiden aikana (kasvukauden pituus) (maan happamuus)

(maan rakenne)

(maan tiivistyminen)

Tulos on ennakko-odotusten mukainen. Kasvukauden pituus, maaperän kemialliset ja fysikaaliset ominaisuudet ratkaisevat juurisadon määrän.

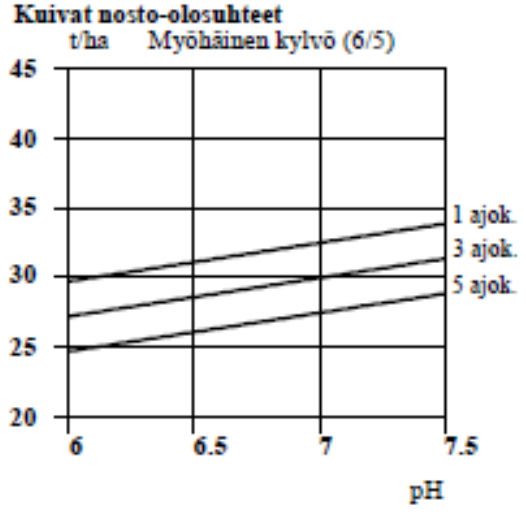

Kuivat nosto-olosuhteet

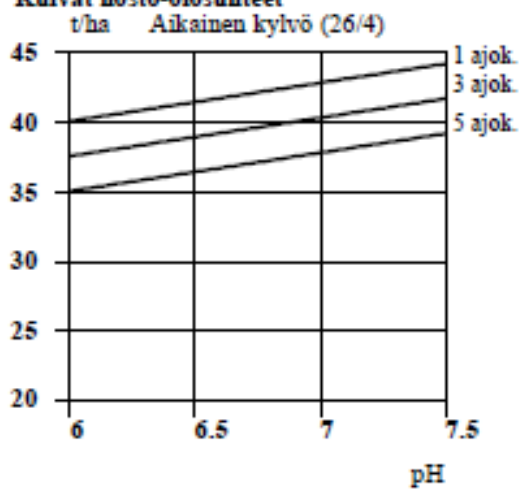

Kuva 1. Juurisadon vaihtelum selittāvät tekijät $\left(R^{2}=54.8\right)$

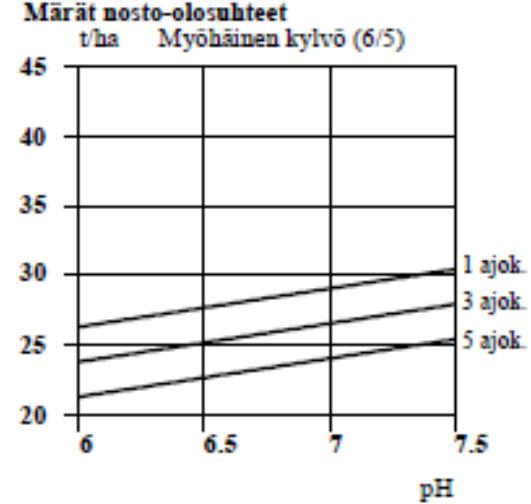

Mārät nosto-olosuhteet

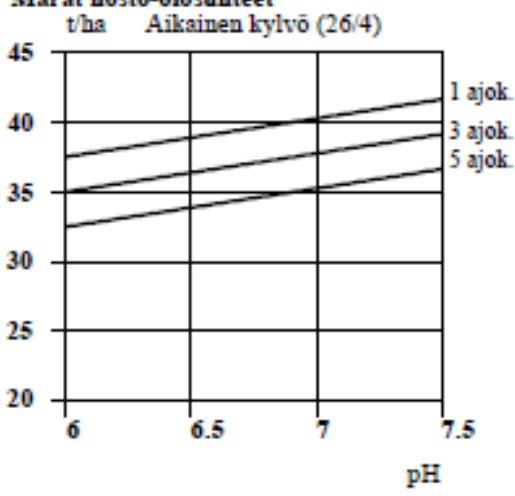

\section{Johtopäätökset}


Suuret akselipainot-projektissa selvitetään sokerijuurikkaan korjuukoneen akselipainon vaikutusta sokerijuurikasmaan tuottokuntoon. Tähänastiset tulokset osoittavat, että suurten akselipainojen tii- vistävä vaikutus näkyy savimaiden maaprofiilissa heti ensimmäisenä vuonna ja toisena vuonna tii- vistymä on edelleen voimistunut etenkin pohjamaassa. Satotuloksiin akselipainolla ei näyttänyt ole- van mitään vaikutusta ensimmäisenä vuonna.

Raskaiden koneiden aiheuttamat maan rakennevauriot näyttäisi olevan niin hidas prosessi, että riittävän selkeiden tulosten saanti edellyttää projektin tavoitteiden mukaisesti vähintään 4 vuoden tarkastelujaksoa.

Projektin sivutuotteena on voitu osoittaa kylvöajan, maan happamuuden ja maan rakenteen mer- kittävä vaikutus sokerijuurikassadon määrään.

\section{Kirjallisuus}

Wadleigh, C.H. 1952: J. Am. Soc. Sugar Beet Technol., 7, 15

Andersson, S. \& Håkansson, I. 1966: Markfysikaliska undersökningar i odlad jord. Grundförbättring 19,3: 191228

Aura, E. 1974: Juurikasmaan rakenteen parantaminen. SaSon Uutiset 4: 5-8

Aura, E. 1983: Soil compaction by the tractor in spring and its effect on soil porosity. J. Soc. Sci. Agric. Finl. 55: 91107

Alakukku, L. \& Elonen, P. 1995: Cumulative compaction of a clay loam soil by annually repeated field traffic in autumn Allison, M. \& Chapman, J. 1995: The role of phosphate in beet crop nutrition. British Sugar Beet Review 63 (4), 1214.

Håkansson, I., Grath, T. and Olsen, H.J. 1996: Influence of machinery traffic in Swedish farm fields penetration resistance in the subsoil. Swedish J. agric. Res. 26: 181-187

Alakukku, L. 1997: Long-term soil compaction due to high axle load traffic. Agricultural Research Centre of Finland, Institute of Crop and Soil Science 